\title{
Rodolfo Lenz: economías de la lengua y políticas de la lingüística
}

\author{
Juan Antonio Ennis* \\ Universidad Nacional de La Plata/CONICET, Argentina
}

\begin{abstract}
Resumen
Este trabajo pretende ensayar un examen de una serie amplia de textos del lingüista alemán radicado en Chile a fines del siglo XIX y comienzos del XX, Rodolfo Lenz, a partir del modo en el cual el mismo trabaja en la instalación en su país de acogida de los métodos e interrogantes de la lingüística moderna en la que se había formado. De este modo, se procura dar cuenta de cómo el trabajo de Lenz en aras de la formación de un espacio y un público para su saber disciplinar, la construcción de un objeto a partir del español hablado en Chile, el mapudungun en contacto con el mismo, las lenguas extranjeras y el acervo narrativo tradicional apuntan a la tarea política de contribuir a la afirmación del español de Chile como una lengua nacional moderna provista de todos los elementos que el dispositivo de las ciencias del lenguaje preveían para tal fin.
\end{abstract}

Palabras clave: Rodolfo Lenz, historia de la lingüística, folklore, economía, colonialismo.

* Para correspondencia, dirigirse a: Juan Antonio Ennis (juanennis@conicet.gov.ar), Centro de Estudios de Teoría y Crítica Literarias, Inst. de Investigaciones en Humanidades y Cs. Sociales, Universidad Nacional de La Plata, Calle 51 e/ 124 y 125, edificio C, 3er piso, 1925, Ensenada, Buenos Aires, Argentina. 


\title{
RudOLF LENZ: ECONOMIES OF LANGUAGE AND POLITICS OF LINGUISTICS
}

\begin{abstract}
This paper aims to sketch a critical reading of several texts by the German linguist who settled in Chile in the late nineteenth and early twentieth century, Rodolfo Lenz, focusing on the way in which he worked on the settlement in Chile of the means and ends of philological research as modern linguistics had come to conceive them at the time. Thus, it shall be attempted to account for how the work of Lenz in order to give form to a proper space and audience for this discipline, the construction of an object based on the Spanish spoken in Chile, the Mapuche language in contact with it, foreign European languages and traditional narratives point to the political task of contributing to the affirmation of Chilean Spanish as a modern national language provided with all the elements that the device of modern language sciences envisaged for this purpose.
\end{abstract}

Keywords: Rodolfo Lenz, history of Linguistics, economy, folklore, colonialism.

Recibido: $15 / 03 / 16 \quad$ Aceptado: 06/05/16

\section{INTRODUCCIÓN: ECOLOGÍA Y ECONOMÍA DE LA LENGUA DADA}

A comienzos de los años 70 del pasado siglo, el escandinavista de Yale Einar Haugen esbozó la propuesta de una "ecología lingüística", un enfoque que pretendía sumarse a las miradas críticas e innovadoras que desde fines de los 50 tendían a abolir la aséptica separación de uso y sistema en las ciencias del lenguaje ${ }^{1}$, a partir del desafío de estudiar las lenguas en sus múltiples, diversos y complejos modos de relacionarse con su contexto y condiciones

\footnotetext{
1 "La ecología lingüística sería una extensión natural de este tipo de estudios, que vienen llevándose adelante hace tiempo bajo nombres tales como psicolingüística, etnolingüística, antropología lingüística, sociolingüística y sociología del lenguaje. Los lingüistas se han ocupado de esto en su trabajo sobre el cambio y la variación lingüística, contacto lingüístico
} 
de realización, ensayando una división del trabajo entre especialidades ya establecidas, otras más bien incipientes y algunas aún por venir, a partir de diez "preguntas ecológicas" que deberían poder responderse para cada lengua dada (for any given language) (Haugen 1972: 59). Más de dos décadas después, Peter Mühläusler retomaría la discusión del concepto de la ecología en la lengua, preguntándose en primer lugar por las razones del escaso éxito de la propuesta de Haugen, que atribuía sobre todo a su "aceptación acrítica de algunas nociones clave sostenidas por el establishment lingüístico", entre las que destacaba su consideración "de que pueda haber algo así como "una lengua dada" y la división discreta de los distintos aspectos de los estudios lingüísticos y sus respectivas especialidades (Mühlhäusler 1996: 4). La idea de una ecología de la lengua que proponía Mühlhäusler ${ }^{2}$ venía a interpelar los fundamentos mismos de la disciplina, sacando del lugar de la anécdota el emplazamiento social de la lengua, su relación con otros códigos, el modo de significar y marcar sus límites y los de la comunidad hablante con mayor o menor labilidad o rigor según el caso, retomando un tópico extendido en la literatura del viaje lingüístico desde el siglo XIX -el de la pronta extinción de la diferencia y la diversidad lingüística ante el avance colonial de Occidente. El subtítulo del volumen, Language Change and Linguistic Imperialism in the Pacific Region, permite pensar justamente en enfoques -presentes en su bibliografía- como los de Calvet (1974) o Phillipson (1992). Concentrado en el examen histórico de las lenguas del Pacífico, Mühlhäusler pone de manifiesto cómo la intervención de las potencias europeas imperiales habría modificado radicalmente, junto con la economía y la ecología, la diversidad y organización de las lenguas, más ampliamente de las formas de comunicación en la región. Destaca así que la tarea de los especialistas puede resultar decididamente invasiva, y que la tarea de identificar, nombrar y describir lenguas, "lejos de ser un acto de descripción objetiva [...] puede constituir una seria intromisión en la ecología lingüística de un área. La misma idea de que las lenguas pueden ser contadas y nombradas puede ser parte de la enfermedad que afecta a la ecología lingüística del Pacíico, y un obstáculo en la reconstrucción del pasado lingüístico" (Mühlhäusler 1996: 5). Y más adelante agregará:

y bilingüismo, y estandarización" (Haugen 1972: 58-59). En todos los casos en los que no se consigna traducción española en la bibliografía, la traducción es mía.

2 La noción de "ecología lingüística" había sido propuesta por primera vez por Voegelin, Voegelin y Schutz (1967), y será retomada y reelaborada nuevamente por parte de Mufwene (2004). Una reelaboración crítica a partir de múltiples parámetros se puede encontrar en Ludwig, Mühlhäusler y Pagel (2016). 
El imperialismo lingüístico, como otras ideologías, tiene su propio lenguaje. Los discursos que lo sostienen [...] son económicos, morales, políticos y científicos (un ejemplo de estos últimos es la lingüística "científica"). Los lingüistas, por mucho tiempo, han argumentado a favor de la neutralidad ideológica de su propia posición, una estrategia que no ha beneficiado ni a su profesión ni a los hablantes de ninguna de las numerosas lenguas que han tomado por objeto (ibíd.: 20-21).

En el mismo año, y desde un lugar excéntrico con respecto al campo de la lingüística, vio la luz un volumen de Jacques Derrida que se ocupaba del mismo problema, a partir de un planteo que insistía asimismo en el carácter incontable (en el sentido del uncountable inglés) de las lenguas. No obstante, añadía, si bien por un lado las lenguas, la experiencia de la lengua como tal, puede ser, en sí, innumerable (la equivalencia, discreción, homologación de las lenguas son operaciones que pueden hacerlas contables en tanto unidades equivalentes, pero que no dan cuenta de todas las experiencias lingüísticas posibles), por el otro admitía que las mismas no dejan de desaparecer por centenares, todo el tiempo. Así, este carácter incontable de las lenguas no impediría ni quitaría dramatismo a la necesidad de la archivación de una de ellas antes de su extinción ${ }^{3}$. Y son estas empresas las que disparan la pregunta acuciante por la necesidad del salvataje de una lengua:

Et s'il valait mieux sauver des hommes que leur idiome, là où il faudrait hélas choisir? Car nous vivons un temps où parfois la question se pose. Sur la terre des hommes aujourd'hui, certains doivent céder à l'homohégémonie des langues dominantes, ils doivent apprendre la langue des maîtres, du capital et des machines, ils doivent perdre leur idiome pour survivre ou pour vivre mieux. Économie tragique, conseil impossible (Derrida 1996: 56) [¿Y si valiera más la pena salvar a unos hombres que a su idioma, allí donde, ¡ay! hubiera que elegir? Pues vivimos un tiempo en que a veces se plantea esta pregunta. En la tierra de los hombres de hoy, algunos deben ceder a la homo-hegemonía de los amos, el capital y las máquinas, deben perder su idioma para sobrevivir o para vivir mejor. Economía trágica, consejo imposible (Derrida 1997: 48)].

\footnotetext{
3 "Pour faire autre chose qu'archiver des idiomes (ce que nous faisons parfois scientifiquement, sinon suffisamment, dans une urgence de plus en plus pressante), comment sauver une langue ? Une langue vivante et " sauve" ?" (Derrida 1996: 56).
} 
La mirada de Derrida no contradice la de Mühlhäusler, sino que la complementa ${ }^{4}$. Allí donde este ve la desaparición de un ecosistema lingüístico, aquel observa el avance irrefrenable de una economía -y no de cualquier economía, claro está. En este punto, resulta decisiva la noción planteada (que no definida, como es habitual), por el filósofo francomaghrebí: homo-hegemonía, que para el lector familiarizado con los estudios de ideologías lingüísticas difícilmente pueda escapar a su asociación con la hegemonía de lo que Blommaert y Verschueren (1998: 202-204) denominarían homogeneism, y que el primero sintetiza como "una ideología en la cual la homogeneidad social, cultural, lingüística y de otro tipo se presenta como la 'mejor' forma de gobernancia [governance]" (Blommaert 2005: 252), y cuya definición y descripción se hacen más precisas luego con la introducción del concepto de "cultura monoglósica" por parte de José del Valle (2000, cfr. Del Valle y Stheeman 2002: 10-11).

Así, hay un modo de ser, asimilar, valorar y gestionar las prácticas lingüísticas que progresivamente se impone a cada comunidad como una necesidad, un destino, una naturaleza dada. Su forma modélica adquiere una primera versión a gran escala con la Revolución francesa, y su lógica económica ha sido analizada eficazmente por Pierre Bourdieu (1982). No obstante, al hablar de las economías de la lengua no se refiere aquí exclusivamente a ese esquema conceptual de la economía de los intercambios lingüísticos, sino que se quisiera comprender allí mismo también el dispositivo más amplio que la hace históricamente posible. Esto quiere decir que, por un lado, la economía de la lengua que se sobrepone a lo que Mühlhäusler daba en llamar su ecología, se comprende aquí en el marco de la integración del saber lingüístico en la maquinaria globalizante de la expansión colonial de Occidente. Por otro lado, se subraya la naturaleza gubernamental, "gestional" de la oikonomía, como ha sido señalada por Giorgio Agamben en su exploración arqueológica de la relación entre economía y política ${ }^{5}$. Esta economía de la lengua concierne no solo al

4 No casualmente, esta vía de reflexión sobre la lengua lo lleva, no sin alguna cautela, a tematizar la colonialidad de la cultura (Derrida 1996: 47).

5 Esto se da en el marco de un estudio (del que aquí, por supuesto, lo mismo que en el caso de Derrida, no se pretende dar cuenta más que a modo de señalamiento) que apunta justamente a indagar los caminos por los cuales el poder adquiere en Occidente la forma de una oikonomía en tanto gobierno de los hombres, procurando proseguir y completar críticamente las investigaciones de Foucault sobre la gubernamentalidad (Agamben 2008: 11). Allí, Agamben (2008: 41-42) ha señalado en Aristóteles la naturaleza "gestional" y no epistémica de la oikonomía en su definición por oposición a lo político: su calidad de ordenamiento práctico, de relaciones naturalizadas, entre hombre y mujer, padre e hijos, amo y esclavos. 
mecanismo de inclusión/exclusión de la lengua legítima, sino que comprende (o nos dice que lo hace), desde su emergencia en el siglo XIX, todo aquello que quedaba fuera: incluye la diferencia, la reduce al orden de lo Mismo y la pone a trabajar en un sistema de producción de valor que sustentará el dispositivo de las modernas lenguas nacionales.

\section{LAS CIENCIAS DEL LENGUAJE Y LA ECONOMÍA DE LAS LENGUAS MODERNAS}

La relación entre la lingüística como discurso autónomo emancipado de fines ajenos al desinterés científico y la forma históricamente más exitosa del imperialismo -el colonialismo moderno- ha sido analizada más recientemente por Joseph Errington (2008), quien da cuenta del modo en el cual la lingüística moderna opera como dispositivo epistemológico integrado a la maquinaria colonial, cuyo principio de acción básico consiste justamente en el aplanamiento de la diversidad lingüística, sobre todo a partir de su profundo interés en la misma. Así, al incorporar esas lenguas a dispositivos de conocimiento definidos, se reduce la complejidad de su emplazamiento y entramado, sus condiciones ecológicas de existencia, integrándolas a un modelo que las hace, justamente, comparables e historizables en relación con la lengua de los señores coloniales. Se observan así dos modos fundamentales en que lo que Errington denomina las "imágenes filológicas de la lengua" pudieron encontrar repercusión más allá del ámbito restringido del saber académico: por un lado, una "visión orgánica de la historia que contribuía a explicar la superioridad de Europa en el presente colonial, naturalizar su avance civilizatorio y dar cuenta de la diferencia lingüística como desigualdad humana en un mundo colonial"; por el otro lado, la filología como una ciencia ante todo alemana, que en un contexto de crisis política y cultural en una Europa en proceso de industrialización "hacía del pasado

\footnotetext{
"Una de las tesis que se tratará de demostrar es que de la teología cristiana derivan en general dos paradigmas políticos, antinómicos pero funcionalmente conectados: la teología política, que funda en el único Dios la trascendencia del poder soberano, y la teología económica, que sustituye a esta por la idea de una oikonomía, concebida como un orden inmanente-doméstico y no político en sentido estricto- tanto de la vida divina como de la humana. Del primero derivan la filosofía política y la teoría moderna de la soberanía; del segundo, la biopolítica moderna hasta el actual triunfo de la economía y el gobierno sobre todo otro aspecto de la vida social" (Agamben 2008: 13).
} 
un recurso para las ideologías nacionalistas" (Errington 2008: 71) ${ }^{6}$. La consideración de esa agentividad política del saber filológico-lingüístico que habría hecho posible la armonización de un diseño global donde a cada comunidad corresponde una "lengua dada", y actúa asimismo como índice de su proximidad a la naturaleza o la cultura, tiene una formulación pionera y extrema en la observación de Michel Foucault acerca del rol discreto pero decisivo de la disciplina cuyo umbral señala en los nombres de Bopp, Schlegel, Grimm y Rask en la modificación nada menos que del modo mismo de ser de la lengua ${ }^{7}$, y encuentra algo más que una expansión o precisión en este tipo de investigaciones que dan cuenta de cómo un proyecto científico en principio restringido a un país sin mayor participación en la expansión colonial europea del XIX alcanza una especial incidencia política en la forma de esa expansión sobre la percepción teórica y la gestión práctica de las lenguas.

No obstante, la eficacia de este programa no puede impedir reconocer la relativa precariedad inicial del terreno sobre el que se asienta la lingüística moderna. Con esto me refiero a la más básica materialidad del trabajo, a sus condiciones mismas de posibilidad. Los casos en que el rol del agente colonial y el del investigador de las ciencias del lenguaje se superponen claramente (puede pensarse en los ejemplos de William Jones o Wilhelm von Humboldt, o incluso del mismo Rasmus Rask, donde la actividad del lingüista se apoya financiera e institucionalmente sobre el aparato propio de las potencias europeas) son más bien la excepción a una regla generalizada que solo avanzado el siglo XIX irá sobreponiéndose, ganando el lugar sobresaliente en el universo institucional de la academia europea que permitirá que la lingüística post-saussureana se erija por décadas en

6 Nadia Altschul, por su parte, habla de "dos formas de conocimiento local europeo expandidas a proyecciones globales: la filología alemana y el paradigma nacionalista" (Altschul 2012: 34).

7 Se hace aquí referencia, claro está, al sub-capítulo de Las palabras y las cosas dedicado a la gramática histórico-comparativa, donde asevera que "toda la obra filológica de Grimm, de Schlegel, de Rask y Bopp permanece en las márgenes de nuestra conciencia histórica, como si sólo hubiera fundado una disciplina un tanto lateral y esotérica -como si, de hecho, no hubiera sido todo el modo de ser del lenguaje (y del nuestro) el que se modificó a través de ellos" (Foucault 2005 [1966]: 275). Poco más abajo, vuelve a poner énfasis sobre este punto, extendiendo esta incidencia de la lengua a la totalidad de la cultura, a su armazón misma: "Sin duda alguna [...], el nacimiento de la filología quedó dentro de la conciencia occidental de manera más discreta que el de la biología y el de la economía política. Si bien formaba parte del mismo trastorno arqueológico. Si bien sus consecuencias se han extendido quizás mucho más lejos dentro de nuestra cultura, cuando menos hasta las capas subterráneas que la recorren y la sostienen" (ibíd.: 276). 
ciencia piloto entre las humanidades. La trayectoria de lingüistas de la talla de Jacob Grimm o August Schleicher ${ }^{8}$ enseña con claridad el alcance de lo que G. Bergounioux asevera al hablar del segundo, esto es, que a mediados del siglo XIX "la lingüística es una disciplina cuya autoridad, conferida por un contenido científico fundado sobre el dispositivo comparatista, es contrabalanceada por la fragilidad de un asiento institucional reducido a algunas decenas de investigadores, dispersos entre cinco o seis países, en situación precaria frente a las posiciones establecidas de la filología clásica" (2002: 7). De este modo, en muchas ocasiones las circunstancias de desarrollo del impresionante edificio de saber que en pocas décadas montarán sobre estas bases los investigadores pioneros de la moderna filología (Grimm, Rask, Bopp, Humboldt, Schlegel) y sus herederos han estado más sujetas al azar que al programa que tras ellas pudiera vislumbrarse. Esto no quiere decir que el resultado último no adquiera la forma de un global design colonial, ni que sus fundamentos ideológicos no respondieran en última instancia por ese destino, sino que muchas veces esto se produce de modos más difíciles de reducir a una sola lógica. Así, si muchos nombres pioneros como los de Jones, Rask o Humboldt muestran una clara relación orgánica entre sus investigaciones y un proyecto de Estado (más allá de las diferencias entre los marcos de cada una, en los tres casos se trata de investigaciones financiadas por un Estado europeo que ve alguna utilidad, alguna forma de recurso en el estudio de la lengua exótica y pretérita), el desarrollo posterior evidenciará, en muchos casos, una relación más mediada. Así, por ejemplo, referentes indudables de la primera y segunda generación respectivamente, como Jacob Grimm o August Schleicher, muestran una relación con el poder que ya no es siempre orgánica, sino muchas veces interrumpida, conflictiva y plagada de contratiempos en la búsqueda de un amparo político para un proyecto de lengua y de disciplina pensado desde la propia posición, un moderno afán de autonomía a cualquier precio (cfr. Ennis 2015, Koerner 1989). Esa voluntad de autonomía esencialmente moderna, connatural al modo en que estos lingüistas podían pensarse políticamente a sí mismos y al lugar de su disciplina en el desarrollo de una sociedad, va acompañada de una clara voluntad de inclusión del otro hasta entonces desdeñado por la alta cultura en su configuración de la lengua y la cultura legítima de la nación para un Estado en vías de modernización.

\footnotetext{
8 Sobre ambos lingüistas he trabajado recientemente (Ennis 2014a, 2015). Remito a esos trabajos para mayor referencia sobre lo que aquí se indica. Se toman aquí como ejemplo ya que se trata a todas luces de los más claros representantes, respectivamente, de la primera y segunda generación de lingüistas histórico-comparatistas.
} 
El relato de comienzos presente tanto en Grimm como en Schleicher da cuenta de una emancipación del saber lingüístico, supeditado en la filología tradicional a la fijación y examen de los textos clásicos, para convertir a su objeto, la lengua, en un fin en sí mismo. La lingüística moderna, así, escapa al libro y a la tradición escrita canónica para abrirse a una forma considerada más "natural" de su objeto, que incluye en esa naturaleza la lengua cotidiana, la cultura popular y la tradición oral y escrita de las lenguas vernáculas. Estas adquieren una dignidad académica antes reservada a las lenguas clásicas, y se comienza a producir un enorme corpus para la divulgación y examen de su dinámica histórica. La filología sale de la biblioteca al mundo, para producir una enorme biblioteca, fundada en la angustia de la falta, del carácter incompleto de la misma y de la pronta desaparición de sus últimos vestigios. Se comienza a producir un corpus inmenso de documentos antiguos, tradiciones populares (relatos, mitos, leyendas, refraneros), literaturas medievales que, encontrando su expresión más o menos modélica en los casos de Rask o Grimm, se extienden hacia todas las ramas posibles de las lenguas indoeuropeas, y se hacen en muchos casos política cultural para la producción y sustento de distintos nacionalismos. Ese impulso de inclusión no excluye la fijación de jerarquías, sino que por el contrario las hace posibles: se trata de la incorporación del otro como material bruto en una economía, un sistema de gestión, archivación, asignación de valores y consecuentemente de roles. El movimiento es democrático y colonial, al mismo tiempo, sin contradicción. Incluye la lengua y la cultura del otro apropiándosela, constituyéndose en su intérprete y mediador, asignándole su valor y forma última.

La economía de las lenguas modernas precisa así, en primer lugar, detectar y poner en valor a través de su elaboración la materia prima de la cultura popular, de esa diversidad que funciona como sustrato fundamental de la unidad común. Desde un lugar de autoridad que encuentra entre sus condiciones de posibilidad y garantías la voluntad de autonomía con respecto a otros saberes y al poder del Estado - del cual debe diferenciarse para poder proveerlo de sus resultados-, el lingüista construye su espacio de enunciación como lugar político, garantía de supervivencia para su labor y sus saberes, para aquello que ve amenazado en su objeto.

De esta manera, la hipótesis de trabajo sobre la que me gustaría comenzar a avanzar aquí en la lectura de algunos textos de Rodolfo Lenz apunta a revisar una vez más su rol en la historia política del español de Chile: cómo su impronta modernizadora, su legado en ese sentido, no tiene que ver necesariamente solo con la instalación y perdurabilidad de un método, sino también con el aporte concreto de un caudal de materiales destinados justamente a reconfigurar la economía de la(s) lengua(s) de Chile de acuerdo 
a los lineamientos proporcionados por la lingüística moderna y saberes afines, y cómo para ese fin debe afanarse en la disputa por un lugar político para su saber, un lugar de enunciación específico, de características propias, desde el cual afirmar la voz autorizada del lingüista en el espacio público.

\section{R. LENZ: EL LUGAR DEL LINGÜISTA Y LAS ECONOMÍAS DE LA LENGUA}

Cuando R. Lenz llega a Chile en 1890, el prestigio de la lingüística moderna podía considerarse sólidamente afirmado, aunque su entramado institucional distaba de estar universalmente extendido. El modo en que Lenz llega a Chile, sin embargo, no es el habitual para los sujetos de lo que podríamos llamar el "viaje lingüístico": no parte de la metrópoli hacia la periferia para recoger sus materiales y regresar a procesarlos, sino que es contratado desde el gobierno del país periférico en el que hallará su objeto de estudio, y no lo es en tanto lingüista sino como profesor de idiomas. Este no es un detalle menor, ya que la enseñanza de idiomas constituía, para la propia autopercepción de la disciplina (cf. Benfey 1869: 1-2), la instancia instrumental superada por la investigación científica, el trabajo del especialista sobre un medio para un fin práctico, externo, frente al trabajo científico que encuentra su fin en sí mismo -aunque para Lenz se convertiría en la llave de acceso a los espacios de intervención posible sobre la forma publica ${ }^{10}$ de su objeto.

Como puede observarse en los distintos momentos de retrospectiva contenidos en la obra de Lenz, su presencia y su labor no dejaron de causar recelo y polémica en distintos sectores de los círculos letrados criollos. El caso de las intervenciones polémicas en la prensa de Eduardo de la Barra, miembro correspondiente de la Real Academia Española y reconocido literato, ha sido retomado recientemente por Nadia Altschul en su Geographies of Philological

9 Esta literatura de viajes científica es la producida por aquellos investigadores provenientes de una institución central que viajan a la periferia a recoger materiales de corpus para llevar a los centros en que serán procesados y dotados de valor, una forma específica de lo que M. L. Pratt (1995) llamaba "literatura de viajes científica". Humboldt, Rask, Jones entran en esa serie, que encuentra un ejemplar bastante claro en las cartas que Schleicher remite desde Lituania a la Academia Prusiana de las Ciencias en 1852, Briefe über die Erfolge einer Forschungsreise nach Litauen, en Schuchardt, o en el propio Lenz, en el recorrido que hace posible su Papiamento (1928).

10 Con respecto a esta noción, véase Ennis (2014b). 
Knowledge (2012), donde lee la contratación de Lenz y Hanssen como el intento, de parte del Estado chileno, de institucionalizar la filología moderna, en lo que llama "the neocolonization of the new nation-state by a 'modern', German-styled philology" (Altschul 2012: 58). De acuerdo con la autora, los "estándares globales de la modernidad filológica" eran internalizados junto con la promesa de que con su incorporación en el "torrente sanguíneo educativo" podía contribuir a correr a las antiguas colonias de la periferia académica a partir del aporte de un modo de producción del conocimiento valorado en la metrópoli. El reconocimiento de la utilidad, prosigue Altschul (2012: 59) de las herramientas de la filología se expresa así en la fundación del Instituto Pedagógico "de acuerdo a directivas europeas" y en la impresión póstuma del Cid de Bello en 1881.

Observando críticamente el rol pionero de Lenz en Chile y la posterior ponderación del mismo por parte de Yakov Malkiel (1968), y recuperando allí algunas de las críticas recurrentes de De la Barra, Altschul resalta la posición neocolonial de ambos filólogos alemanes trasterrados frente al síntoma notable de la falta de discípulos o "escuela" en materia lingüística para Lenz y Hanssen. La oposición entre la resistencia del letrado criollo De la Barra como figura del settler colonist y la mirada europea neocolonial se encuentra, sobre todo, en el lugar donde se pone la responsabilidad por la acusada esterilidad de la labor de los filólogos alemanes en suelo chileno. Así, si la resistencia criolla de De la Barra imputaba a la impericia del maestro la ausencia de discípulos, la mirada neocolonial que Altschul encuentra en Malkiel responsabiliza por ello a la falta de preparación del medio y el público mismos para dar una continuidad a su trabajo ${ }^{11}$.

El problema, sin embargo, considerado más de cerca, presenta otras aristas que merecen ser tomadas en consideración, y más allá de que algunos

11 "Mientras de la Barra encuentra la falta en los maestros, que no tuvieron la capacidad o la voluntad para capacitar discípulos que pudieran reemplazarlos, Malkiel trabaja más cerca de una actitud colonialista. De la Barra es incrédulo con respecto a la valía de los pedagogos incapaces de capacitar siquiera a un sustituto adecuado para sus puestos, mientras Malkiel, probablemente sin advertir los tonos imperialistas de su propio discurso, ve en cambio una falta de inclinación de parte de los chilenos hacia los más valiosos, si bien arduos, esfuerzos de la filología 'moderna'. El problema, de hecho, no se resolvió otorgando al instituto tiempo suficiente para capacitar alumnos locales. Después de la temprana muerte de Hanssen en 1919, Lenz lamentaba que no hubiera reemplazo local para su colega, debiendo por lo tanto tomar su puesto en la gramática histórica él mismo. El motivo esta vez era que ninguno de sus estudiantes 'fue a estudiar filología románica a Europa'. Como temía de la Barra, los pedagogos formados en Alemania no nivelaron el terreno de juego académico sino que concentraron recursos académicos en ellos mismos; incluso tres décadas después de su llegada, no encontraban a nadie entre sus estudiantes locales para recomendar como reemplazo" (Altschul 2012: 67). 
ensayos de historiografía disciplinar sí encuentran elementos para reponer una cierta continuidad en la tradición de estudios lingüísticos abierta por Lenz (Valencia 1993) y un claro cambio en el modo de estudiar la lengua a partir de su llegada a Chile ${ }^{12}$, la distribución de las actividades del propio Lenz es más rica y compleja como para solo buscar la fecundidad de su legado en el mismo Instituto Pedagógico, por un lado, y tiene un componente político ligado a la precariedad institucional de su posición como lingüista que no debe ser pasado por alto. En este aspecto, la resistencia de los que llama "profesores antiguos" a la difusión de su magisterio más allá de su ámbito directo de enseñanza imponía trabas efectivas para el desarrollo profesional tanto de Lenz como de sus discípulos ${ }^{13}$.

Lenz mismo irá construyendo los espacios para su labor científica desde su lugar de trabajo y apelando a todos los medios posibles de la publicidad para su difusión y discusión, sin dejar de subrayar constante, recurrentemente, la precariedad de su posición periférica, con respecto al centro de producción del saber filológico y con respecto al poder de regulación de la norma. En este sentido, hay una paradoja fundamental en la construcción de su espacio y rol como enunciador de un discurso autorizado sobre las distintas lenguas de su especialidad, que se explica directamente a partir de la excepcionalidad de su posición. Es, por un lado, un especialista europeo, proveniente del corazón mismo de la filología románica (se había doctorado en Bonn con Foerster, sucesor de Friedrich Diez), que se ocupa intensivamente de un objeto complejo y múltiple: el español de Chile en su variación, cambio y diversidad, los diversos dialectos del mapudungun o "araucano", las relaciones de contacto entre ambos y las formas de la cultura popular. $\mathrm{Su}$ formación, su natural pericia para el aprendizaje de lenguas y su afán de investigador hicieron que muy rápidamente, contratado como profesor de lenguas, se estableciera como uno de los más reconocidos especialistas en el estudio del español americano y el mayor en el estudio del mapudungun

12 En los últimos tiempos, trabajos como los de Darío Rojas (2011) en torno al epistolario con Echeverría Reyes comienzan a dar un fundamento empírico sólido al cambio operado en el modo de estudiar los fenómenos lingüísticos en Chile a partir del arribo y labor de Lenz y Hanssen. En el propio trabajo de Rojas puede encontrarse un completo estado de la cuestión que informa de manera clara sobre los antecedentes de la investigación en este sentido.

13 Rabanales (2002) se ha ocupado de rastrear en el archivo rasgos de lo que el propio Lenz aseguraba en su conocido discurso de 1920 sobre "La enseñanza del castellano y la reforma de la gramática": para formar escuela se necesita un marco institucional: "Los profesores jóvenes no se atrevían a aplicar en la enseñanza escolar las teorías científicas modernas que habían aprendido en el Instituto Pedagójico, porque con razón temían la oposición de los profesores antiguos, que estaban en las comisiones examinadoras" (Lenz 1920: 18). 
y el contacto entre ambas lenguas. Lenz marca ese campo a través de sus publicaciones en Chile y Alemania. Solo el examen del índice de los Anales de la Universidad de Chile en la última década del siglo XIX y las dos primeras del XX permite ver el lugar preponderante que asume en el horizonte de las investigaciones científicas en el país, justamente en uno de los principales organismos responsables de su organización y difusión.

Ese marco institucional no estará solamente dado por su docencia, sino también por sus investigaciones, viajes, contactos y sobre todo por sus publicaciones. No es solo en la cátedra que debía buscarse el legado, sino también en otros ámbitos de su especialidad, como la enseñanza de idiomas (Escudero 1963, Velleman 2008), o más aún el folklore, donde se evidencia una continuidad más clara en su trabajo pionero (Escudero 1963). Así, si bien quizás la "neocolonización del Estado-nación" por parte de la filología representada por Lenz podía resultar una sobreinterpretación de su rol efectivo, el modo de ser colonial de la lingüística en la obra de Lenz se puede comenzar a observar en esa articulación entre la promoción de una economía de la(s) lengua(s) y una política de la lingüística. Una economía que aparece como condición de posibilidad de cualquier lengua moderna que se pretenda viable como lengua nacional, y que incorpora lo que la gramática normativa excluía en la forma del sustrato o la materia prima de los rasgos distintivos de la lengua nacional, de aquello que debe resultar más propio y reconocible, y que a la vez precisa de la tutela del letrado. Las políticas de la lingüística son las que en este caso hacen posible el emplazamiento de este saber en el espacio público, su búsqueda de una relativa autonomía, siempre precaria, y su diálogo con el Estado.

La distribución de los trabajos entre dos públicos, uno chileno por formar y otro alemán especializado, no impide sin embargo que, de distintos modos, los mismos trabajos vayan publicándose en las dos lenguas, y si bien esto sucede muchas veces con décadas de distancia ${ }^{14}$, en aquellos en los cuales lo que interesa es marcar el terreno, se da prácticamente de manera simultánea: así su tan minuciosa como virulenta crítica del volumen de Raoul de la Grasserie publicado como tomo 21 de la Bibliothèque de Linguistique Américaine de la editorial Maisonneuve, con el nombre de Langue Auca (ou

14 El caso más conocido probablemente es el de los Indianische Elemente im chilenischen Spanisch (Halle, 1902), convertido en el volumen de 1940 en la Biblioteca de Dialectología Hispanoamericana de Amado Alonso y Raimundo Lida) aunque también puede considerase lo que él mismo presenta como una "anomalía literaria" en la publicación poco menos de un cuarto de siglo después del texto sobre la poesía popular impresa en Santiago (Lenz 1919: 511-512). 
langage indigène $d u$ Chili), aparecerá simultáneamente en ambos idiomas (Lenz 1898a, b) ${ }^{15}$. Como se ha mencionado y documentado en trabajos anteriores (Ennis 2012), Lenz aclara permanentemente los términos de esta división, excusándose ante su potencial lector europeo conocedor de la disciplina por dar explicaciones que a esta altura parecerían superfluas, pero resultan sin embargo necesarias para el público local. Así, aún en el prólogo a Los elementos indíjenas en el castellano de Chile, dando cuenta tras dos décadas en el país de una labor lexicográfica cuya novedad revolucionaria ha descripto recientemente Chávez Fajardo (2011), se preocupa Lenz por aclarar su posición descriptivista y no prescriptivista, y antes de explicar sus razones debe excluir prudentemente al lector especializado:

He de permitirme algunas observaciones en este punto, no porque sea indispensable para mi trabajo presente, pues yo no voi a censurar ninguna palabra chilena; tampoco será necesario que lean los párrafos siguientes los filólogos europeos en cuyas manos caiga por suerte mi libro. Pero invito a los lectores americanos a que me sigan un momento, para que comprendan mis propósitos (Lenz 1910: 10).

Nuevamente, la descripción de los dos circuitos puede verse al menos de dos maneras, que no son mutuamente excluyentes. Por un lado, la minorización del público local frente al más avanzado lector metropolitano podría sumarse a la lista de gestos neocoloniales atribuibles al autor. Por otro lado, dentro del marco de la dispersión global de la lingüística moderna, hay algo poco habitual, hasta novedoso, en el dato que puede extraerse de aquí: Lenz no asume el lugar del viajero científico que encuentra un solo interlocutor válido en el colega metropolitano, sino que dirige su discurso en dos direcciones: la de un campo científico en formación, y la de uno establecido. Al mismo tiempo que desde muy temprano se afana en mantener el vínculo y asegurarse la recepción y el diálogo con sus colegas europeos ${ }^{16}$, la insistencia y

15 Aunque cabe aclarar que el ámbito de publicación es en ambos casos chileno, ya que la versión alemana se publica en un medio de divulgación de la actividad científica alemana en Chile. Curiosamente, hay dos elementos de la versión alemana ausentes en la española: la mención irónica de la titulación del autor (Dr. Jur., proviene del ámbito del derecho, no del de la lingüística) y el subtítulo: "Eine Warnung für Amerikanisten" ("Una advertencia para americanistas").

16 Silvio Moreira de Sousa y Johannes Mücke (2016) recuperan el siguiente fragmento de una carta a Schuchardt de 1892, agradeciendo la recepción y comentario de su trabajo "Glauben Sie, verehrter Herr Professor, es tut einem hier doppelt wohl, zu erfahren, daß man noch nicht von allen Fachgenossen in Europa vergessen ist und ein solcher kleiner Ansporn ist hier nötig um nicht den Mut zum wissenschaftlichen Arbeiten zu verlieren, das bei dem Mangel von Bibliotheken und der Entfernung von den Druckorten nur eine halbe Freude ist 
persistencia de su trabajo e intercambios a nivel local y latinoamericano dan cuenta del afán de formación de un campo y un público idóneos para la discusión de sus temas. Esta suerte de afán pastoral secular del lingüista no es novedoso en sí, y encuentra un ejemplo claro y fundante en Die deutsche Sprache de August Schleicher (1860), que se definía a sí mismo como un intento de instruir al público lector en los misterios de la lingüística y en el amor de la lengua en su diversidad, en la comprensión de esa diferencia como riqueza, patrimonio de la nación (cfr. Ennis 2014a). Lenz, que conocía bien la obra de Schleicher y la consideraba un eslabón fundamental en el desarrollo de la disciplina ${ }^{17}$, traslada este gesto a su espacio de adopción. De lo que se trata es no solamente de modernizar el discurso sobre la lengua, sino la lengua misma, la conciencia que de ella se posee y su lugar -central, por cierto- en la concepción de una identidad nacional. Lenz postula desde fecha temprana, en las dos lenguas y para ambos públicos, una "diferencia chilena", una superioridad [Überlegenheit] fundada en la uniformidad de la población, su lengua y cultura y las peculiares condiciones de su formación, en la guerra entre el español y el indio. Así, en el primero de los "Ensayos filolójicos americanos" se ofrecían estas apreciaciones ya en español:

No hai ningún país sud-americano en que los indios actualmente tengan un papel tan poco importante como en Chile. Fuera de aquel territorio de la Araucanía, cada año más restrinjido, en todo el país hai desde la costa hasta la falda de la gran cordillera una sola lengua, la española; una sola raza, la chilena, que debe su orijen a la fuerte inmigración de soldados españoles, los que se mezclaron naturalmente con las mujeres indias. I no se debe creer que los hombres indios hayan sucumbido todos en la guerra contra los invasores. Seguramente muchos miles de ellos han aceptado la lengua i las costumbres de sus antiguos enemigos, como hasta hoy se puede observar tan a menudo en las provincias de la frontera (Lenz 1894: 131).

[Créame, admirado Profesor, hace doblemente bien saber que uno no ha sido olvidado aún por todos los colegas en Europa, y un estímulo así es aquí necesario para no perder el ánimo para el trabajo científico, que con la falta de bibliotecas y la distancia de los lugares de impresión, es sólo una satisfacción parcial]" (Lenz a Schuchardt, julio de 1892; No. 06397).

17 En el artículo propedéutico que firma junto a Barros Arana, "La lingüística americana. Su historia i estado actual" (en la sección que, de acuerdo con Vilches (1938) habría correspondido a Lenz), se traza una breve introducción a la historia de la lingüística moderna, que, abriéndose con la mención de William Jones, pasa por los nombres de Schlegel, Bopp, Grimm y Pott, encuentra un punto de llegada en Schleicher, cuya tipología evolutiva tripartita reseña brevemente, tomando sin embargo distancia de ellas, para pensarla en términos de un conjunto de categorías no discretas, sino combinables y graduales (Barros Arana y Lenz 1893: 28). 
El relato que Lenz propone para fundar una identidad chilena "sana" en términos del nacionalismo moderno, esto es, surgida del contacto pero lingüística y étnicamente uniforme al fin, fundada en el hegeliano progreso de la historia hacia occidente, incluye al llamado "pueblo bajo", al roto y al huaso $^{18}$, de acuerdo al esquema adquirido, como depositario virtual, sustrato y productor de la materia prima a partir de la cual se elabora el patrimonio para la cultura de la nación, e incluye también al indio, con la sola condición de su previo exterminio o asimilación. La excepcionalidad chilena reside justamente, según Lenz, en que al momento de la independencia "el indíjena estaba absorbido por completo", lo cual no significa su eliminación de la ecuación (paradójicamente, a pesar de la legitimación de su exterminio), sino su inclusión fundante pero residual en el relato de identidad: "los araucanos, los enemigos mas feroces de los españoles, han dado oríjen a la mas fuerte nación española del Nuevo Mundo" (ibíd.) ${ }^{19}$. Así, el final del estudio da su lugar político a la especialidad en esta economía de la nación:

Pero es un hecho, la historia lo ha probado muchas veces, que la fuerza nacional no reside en unos pocos gobernantes sino en la masa numérica del pueblo bajo, en esa fuente rejeneradora que nunca se acaba. [...] Pues si, en último término, Chile debe lo que es a su pueblo bajo, a esa raza de sangre mezclada española i araucana, no parecerá ya un asunto de poca importancia el indagar las especialidades del lenguaje del huaso chileno. Al contrario, nos parece un deber patriótico de todo chileno instruido colaborar en tales trabajos, si puede, o al ménos estudiarlos, como es deber de todo instruido el estudiar la historia política de su nación (Lenz 1894: 132).

En estas líneas finales del artículo se identifican claramente al menos tres sujetos: el huaso o pueblo bajo, cuyas características son la indefinición de la masa y el mestizaje, los "pocos gobernantes", y el "chileno instruido" -la "gente educada" que debía dar el modelo de la corrección gramatical en

18 Acerca del contexto histórico propicio brindado por la posguerra del Pacífico, puede verse la tesis de Concha (2015: 29-30).

19 Posteriormente, en el prólogo al ya citado diccionario, Lenz dará expresión a esta idea -recurrentemente expresada en sus trabajos- a través de una metáfora interesante y sugestiva, la de las cicatrices: "No hace un siglo todavía que los chilenos se gloriaban de ser descendientes de la mas valerosa raza americana por la mitad de su sangre. En mi libro verán sin falsa vergüenza hasta qué grado le deben también la lengua, su pensamiento. Este enorme número de palabras araucanas i quechuas incorporadas en la lengua castellana son como las cicatrices de la lucha jigantesca en que el español de Chile venció al indio de Chile, i lo obligó a aprender un idioma europeo i a formar con él una nacionalidad nueva i firme, la más sólida i homojénea que se enjendró en suelo americano pisado por español” (Lenz 1910: 41). 
Bello-, cuyo deber es conocer a ese otro y su lengua, ya que constituye la fuente primera del ser nacional. La forma extrema de la diferencia, el indio, se incorpora a la fórmula de la identidad nacional solo de manera residual, como elemento asimilado, ya que el destino de su existencia autónoma aparece ya irreversiblemente sellado ${ }^{20}$.

La unidad última de esos elementos viene finalmente garantizada por el especialista: no solo por su juicio acerca de la pertenencia común de una serie de elementos lingüísticos y extralingüísticos, de fonemas y lexemas como de comunidades, sino por lo que les hace decir. Así, al presentar en el XVII Congreso de Americanistas en Buenos Aires los resultados de su trabajo lexicográfico, aclara: "No habrá ningún chileno vivo que conozca siquiera la mitad de todas las palabras que tengo apuntadas, pero créanme que no he inventado ninguna palabra, si bien yo o mis colaboradores somos mortales espuestos a error" (Lenz 1912a: 6). Esos materiales se presentan como el "caudal" de las ideas del pueblo chileno, en una concepción que permite ver claramente la influencia no solo de la Völkerpsychologie de Wundt, sino sobre todo las concepciones acerca de la relación entre lengua, nación y civilización tal como aparecen primero en Grimm, y luego en Schleicher y Pott $^{21}$. Lenz incorpora esta genealogía prestigiosa a su descripción del campo, pero la actualiza desde su observación y el presente, procurando conciliarla con los desarrollos más recientes en la disciplina, tanto en el caso del más visible Wundt como en las aparentes antípodas de la posición schleicheriana en Hugo Schuchardt, sintetizadas en su conocida afirmación acerca de la inexistencia de lenguas completamente carentes de mixtura (Es gibt keine völlig ungemischte Sprache, Schuchardt 1885: 5). Lenz afirmará por su parte que, "así como no existen pueblos de raza absolutamente pura

20 No solo los componentes son importantes en este desarrollo, sino también el modo: "El desarrollo de la nacionalidad chilena ha sido paulatino i parejo i, por consiguiente, sano", dice en un estudio posterior, agregando un prejuicio difícil de matizar aún por el más benévolo de los lectores: "El elemento africano felizmente en la más pobre de las colonias, que no producía ni oro, ni azúcar, ni café, ni tabaco, nunca ha tenido gran importancia, i aún en el último siglo ninguna inmigración europea ha sido tan fuerte que haya podido alterar el carácter de la nación chilena, como quizá sea el caso en Arjentina con los elementos italianos" (Lenz 1919: 518-519).

21 "La gramática de una lengua enseña cómo piensa el pueblo, es decir, expone en forma sistemática i jeneral hasta qué grado corresponden o no corresponden las leyes de su idioma a las categorias lógicas i a los fenómenos sicológicos que se observan en el pensamiento humano en jeneral. Tal estudio se refiere a la forma del lenguaje. En cambio en el diccionario aprendemos cuáles i cuántos son 1 os conceptos claros e independientes a cuya formacion ha llegado la evolucion siquica de1a nacion, conocemos el material del lenguaje, el caudal de sus ideas" (Lenz 1912a: 3). 
i única, así tampoco existen lenguas que no hayan recibido voces de sus vecinos" (1912a: 3), y desde el comienzo de sus investigaciones sobre el español de Chile, en la línea de Schuchardt, cuestionará las explicaciones monocausales basadas en la "espontaneidad" de la evolución de la lengua para dar un lugar privilegiado al contacto ${ }^{22}$.

La posición de Lenz, entonces, se define entre el prestigio de su formación y la precariedad de su posición, por un lado, en lo concerniente al saber disciplinar, y por el otro, en cuanto a las lenguas en que se especializa, entre la posición del pionero y mayor especialista ${ }^{23}$ y la relativa soledad del innovador ante la tradición normativa secularmente asentada en el país. La primera política del lingüista en este sentido será la de nombrar su espacio, modificando el nombre de su cátedra de Gramática Castellana por el de "Lingüística castellana" ${ }^{24}$, y bregar desde allí por la imposición de los términos del saber moderno sobre las lenguas, aquellos en que cimienta su prestigio: el primero y quizás más repetido de ellos es el que impugna la consideración de Bello de la gramática como arte (saber práctico, instrumental) y la exigencia de considerar a la misma como ciencia (saber que encuentra su fin en sí mismo). De inmediato comienza a introducir, en los Anales, los lineamientos de su investigación. El artículo de 1892 titulado "La fonética" funciona así como una introducción a la especialidad en la que se había formado, cuyo carácter inédito en lengua española subraya en nota al pie, y proporciona una apretada introducción a su estudio, que insiste en su utilidad teórica y práctica, para la lingüística y la enseñanza de idiomas,

22 Pienso aquí, claro está, en la conocida polémica con los Junggrammatiker en torno a las leyes del cambio fonético (Schuchardt 1885). Véase por ejemplo la siguiente observación: "Es claro que las divergencias del español americano con respecto al castellano pueden basarse en principio en el llamado desarrollo espontáneo. Pero es necesario indagar en cada caso particular, si con la palabra desarrollo 'espontáneo' no estamos queriendo solamente ocultar nuestro desconocimiento. ¿Hay entonces un algo así como un desarrollo fonético espontáneo? Estrictamente, no. Puesto que todo suceso tiene sus causas, y cuando se permite hablar de desarrollo fonético, se lo hace solamente en el sentido de que el cambio fonético no es inducido por los sonidos vecinos, es decir que no es asimilatorio, sino a través de causas internas desconocidas para nosotros. Entre estas causas la influencia etnológica es tan sencilla de advertir teóricamente como difícil de demostrar en la práctica" (Lenz 1893b: 191), en los "Beiträge zur Kenntnis des Amerikanospanischen", o en los "Ensayos filolójicos americanos": "Lo que sí sabemos es que en todo caso es inadecuado comparar un cambio fonético con un esperimento de física" (Lenz 1894: 119).

23 Lugar refrendado por Meyer Lübke (1920: 225, la única lengua romance extraeuropea sobre la que poseemos información fiable es el "chileno").

24 "Cuando hace veinticinco años, me hacía cargo de la nueva cátedra de castellano, ésta, a indicación mía, no se denominó simplemente "gramática moderna" en oposición a la cátedra del señor Hanssen, que era la "gramática histórica" [...], sino que se le dio el nombre de "lingüística castellana" (Lenz 1920:12). 
respectivamente (Lenz 1892: 907) 25 . Una función análoga cumple el artículo propedéutico y programático publicado al año siguiente (Barros Arana y Lenz 1893), sobre lingüística americana, o la introducción al "método directo" en la enseñanza de lenguas vivas (Lenz 1893b), entre otros.

La segunda política del lingüista consiste en ir a la busca de su objeto: la lengua de acogida, el español de Chile. La novedad de ese estudio, insistirá una y otra vez, reside en dos puntos: el recorte de la lengua popular, por un lado, y por otro, el consecuente carácter descriptivo-explicativo y no normativo de su labor. En el primero de los "Ensayos filolójicos americanos" Lenz realiza una puesta en escena de esta búsqueda, en la cual comienza afirmando, desde la primera persona del plural, la necesidad de estudiar el español americano: "Debemos indagar mas de cerca las bases i los fundamentos del lenguaje actual de la América española", para introducir seguidamente una voz que pregunta si esa no es "el castellano, la lengua de Cervantes i Lope de Vega, la lengua que habla la Real Academia Española", a la que responderá que sí, pero esa es "la lengua de los letrados", que de todos modos ningún americano posee completamente, ni tampoco "me interesa nada":

"Pero no hai otra lengua en América, me dirá el lector, a no ser que hable de las lenguas indíjenas."

Sí, hai otro lenguaje mas en Chile; un lenguaje despreciado, es verdad, pero bien conocido de todos i a cuyas influencias ningún chileno, por ilustrado que sea, puede sustraerse completamente; este lenguaje, en que me ocupo, al cual atribuyo tanto interés lingüístico, es la lengua castellana tal como se habla entre el pueblo bajo, sin instrucción, es el lenguaje de los huasos chilenos (Lenz 1894: 122-123).

Como subraya el propio Lenz al repasar posteriormente su trayectoria, el estudio de la lengua popular lo obligó a dirigir su atención a la lengua de los indios de Chile. Tanto en el estudio de la lengua popular como en el del mapudungun, Lenz desarrolla una tarea pionera, invalorable, que la cultura monoglósica de Estado que aparece como único horizonte posible en la formación de la mayor parte de los estados americanos hubiera obnubilado por completo. Sin embargo, hay dos rasgos fundamentales para entender esta empresa, desde los términos aquí propuestos. Políticamente, el horizonte homogéneamente monoglósico es observado como una virtud, la diferencia chilena que Lenz valora frente a las demás naciones hispanoamericanas.

25 Acerca de Lenz como fonetista puede verse el trabajo de Petursson (1989), así como el homenaje de A. Alonso (1938) en el volumen publicado tras su fallecimiento. 
La lengua y cultura mapuches funcionan aquí como un sustrato que debe, sí, registrarse, archivarse, antes de su desaparición, lógica y políticamente necesaria. Y en este sentido, la labor antropológica del lingüista se incorpora en un diseño global de las disciplinas en cuestión. En el artículo firmado junto a Barros Arana en 1893 puede observarse con claridad tanto la inscripción en ese proyecto global (que luego se afianzará a partir del contacto con Franz Boas) como la consideración de la necesaria desaparición del otro "es de esperar que, cuando en un siglo más hayan desaparecido la mayor parte de las tribus indígenas, la ciencia sabrá al menos quiénes fueron esos aborígenes", Barros Arana y Lenz 1893: 33). Esto le permite señalar la necesidad y urgencia del trabajo emprendido, que irá satisfaciendo con la aparición sucesiva en los años siguientes de sus Estudios araucanos, también en los Anales. La lengua de los indios de Chile debe ser estudiada no solamente por su valor como corpus exótico novedoso en el panorama global de la comparación entre lenguas como método científico por antonomasia, sino sobre todo porque permite explicar el desarrollo de la lengua popular, y la lengua popular debe serlo tanto por su valor como "fuente" o patrimonio, como por el hecho de que "el estudio de los dialectos vulgares da los materiales más interesantes para comprender la evolución histórica del lenguaje humano" (Lenz 1940: 17), y a medida que el sujeto de ese conocimiento va extendiendo su dominio, su labor civilizatoria, el objeto en cuestión se irá desdibujando. Por otro lado (y de hecho esta es la reflexión previa a la determinación de la necesidad de su estudio), el español americano cuenta con la ventaja de que las lenguas de sustrato aún subsisten -si no por mucho tiempo- y guarda así un potencial explicativo para la historia de la lengua a nivel metropolitano y por lo tanto global. Como se hace claro en estas mismas páginas, un caso como el chileno daba la clave para demostrar empíricamente lo que teóricamente era claro para la historia del latín y las lenguas romances pero prácticamente difícil de demostrar dada la imposibilidad del acceso a datos directos de las lenguas prerrománicas (las lenguas "indígenas" de Europa, como las designa la terminología no solamente de Lenz): la incidencia (y preeminencia) del contacto en el cambio lingüístico por encima de supuestas leyes inalterables de la evolución en el sistema ${ }^{26}$.

26 Un ejemplo claro se desarrolla en el ya referido primer ensayo de los "Estudios filolójicos americanos", donde Lenz parte del ejemplo del modo en que puede accederse al conocimiento del latín vulgar a partir de los rasgos comunes entre las lenguas romance, de cómo testimonios indirectos permiten tomar conocimiento de una lengua hablada largamente distante de la de Cicerón. Las diferencias podrían explicarse, en principio, por la diversidad 


\section{EL FOLKLORE}

"El estudio comparado de los cuentos populares forma hoi en todos los paises cultos una de las ramas mas interesantes i difíciles del folklore" (Lenz 1911: 685).

Esta es la frase inicial del trabajo introductorio de Lenz a su reunión de "Un grupo de consejas chilenas", empeño al que da el subtítulo de "Estudio de novelística comparada precedido de una introducción referente al oríjen i la propagación de los cuentos populares". La adscripción de Lenz a este tipo de estudios, más allá de su actualización en formas más especializadas de la antropología ${ }^{27}$, se inscribe en lo más conspicuo de la tradición de la lingüística decimonónica, en su establecimiento como disciplina científica a partir de la diversificación de las prácticas textuales de la filología y en su contribución fundamental para el acopio y capitalización de un patrimonio para la nación que debía dar cuerpo al Estado moderno. El ejemplo, claro está, es el de los Grimm, en su recolección, elaboración, sistematización y estudio de las fuentes diversas de la literatura popular, que da forma a una tipología que será a grandes rasgos la que retome Lenz en las páginas siguientes de su ensayo. Las tres categorías serán la de conseja, cuento tradicional y leyenda, donde la novedad del arcaísmo "conseja" procura traducir aquello que diferencia al Märchen del cuento y la larga vacilación del "cuento tradicional, la tradición o leyenda histórica (opuesta a la historia documentada)" pretende parafrasear el alemán Sage, términos que contaban

de las lenguas que entraron en contacto con la del Imperio en las distintas regiones, aunque la escasez de documentación haría difícil la demostración práctica de estas hipótesis, más allá del léxico, que es visto como el lugar más sujeto al azar y lo anecdótico, en el terreno que, según Lenz, mejor caracteriza a cada lengua: "su gramática, es decir [...] el conjunto de las leyes fonéticas que la rijen, [...] las peculiaridades i tendencias de su morfología i por su construcción sintáctica" (Lenz 1894: 116-117).

27 Ya en nota al pie en este mismo trabajo refiere a Franz Boas, recurriendo a su autoridad para indicar que "hasta hoi no hai ninguna prueba científica de que la raza blanca sea de suyo superior a alguna de las demás". Esta "ley fonética", sin embargo, no es universal, sino que está vinculada directamente a las formas de analogía que entran en juego y a la "frecuencia de uso". Páginas más adelante, Lenz (1894: 118sigs.) plantea una discusión de la noción de "ley fonética" que descarta de plano los rasgos más polémicos de la misma, acercándola más a la forma de una regularidad observable en los datos empíricos que a la de un proceso riguroso y sin excepciones, en un deslinde que lo sitúa claramente (y en contra de los argumentos que esgrimirán luego sus más encumbrados detractores) más cerca de Schuchardt que de los Junggrammatiker. 
con dos obras fundamentales de los hermanos Grimm, los Kinder und Hausmärchen y las Deutsche Sagen.

Esta frase inicial da cuenta en su forma misma del proceso que quisiera describir aquí. La mención de la especialidad del estudio, más allá del mero hobby del coleccionista amante de su lar, marca el límite inicial y el final del enunciado, entre el "estudio comparado" del comienzo y el énfasis en la dificultad de lo que a primera vista serían solo cuentos, en una rama específica que se está procurando asentar institucionalmente: el folklore. Y entre estos dos extremos, los dos términos articulados en torno al "hoy": cuentos populares/países cultos. La representación del modo de ser de una nación comprendía tanto la posesión de una lengua propia ${ }^{28}$ como de un acervo tradicional. En casi todos los casos, esas tradiciones recogidas por el especialista son evaluadas como tesoro, bien, patrimonio de la nación. Es significativo que entre los cuentos populares y los países cultos medie justamente el adverbio "hoy", ya que justamente esta articulación entre la cultura que sistematiza el saber, archiva la tradición y asegura su valor como patrimonio ${ }^{29}$ y aquella que lo produce $u$ ofrece como materia prima es una forma clara y recurrente de la economía de la lengua y la cultura en la modernidad y la contribución de estas disciplinas a su modelado, que contribuye a escindir (a veces nostálgicamente) el pasado de la tradición recogida y el presente de la modernidad que anuncia su ocaso.

En este punto, sigue siendo referencia ineludible el capítulo dedicado por Bauman y Briggs (2003) a los Grimm, especialmente en lo referente a su intervención sobre el género del Märchen, su forma, sentido y circulación. A través del análisis de las distintas etapas en la elaboración, edición y reedición de los $K H M$, estos autores indagan el modo en el cual los Grimm hacen del Märchen un género homogéneo y tipificable. Así, ponen de relieve cómo un trabajo que encuentra en su génesis la discusión en torno a la ideología de la autenticidad (Echtheit) en la transmisión vernácula (Bauman y Briggs 2003: 207), donde los Grimm oponen su valoración del carácter auténtico de la cultura popular recogida directamente en sus fuentes al desdén de sus

28 La opinión de Lenz en este punto no puede circunscribirse sin más al esquematismo habitual, que él mismo se ocupa de descomponer en un breve ensayo titulado "Nacionalidad y lenguaje" (Lenz 1893c): allí puede verse que para Lenz no se trata sencillamente de la relación orgánica una nación = una lengua, sino que Lenz ofrece una visión más compleja, articulada sobre una concepción clara de la diversidad de la lengua y la cultura popular.

29 Es el caso, por ejemplo, de los refranes y narraciones recogidos por Schleicher en Lituania, donde su biógrafo no duda en aseverar que con ellos se asegura a la nación "su propiedad literaria, un trozo de literatura popular" (Lefmann 1870), o de las Deutsche Sagen (1816) de los Grimm. 
predecesores (como Brentano y Achim von Arnim) por la falta de valor estético de los mismos, de acuerdo a los patrones de la "alta cultura", finalmente interviene masiva y decisivamente sobre su forma y contenido para hacer de ellos un género con características propias y un producto viable en la academia y el mercado.

[...] los esfuerzos de los Grimm para hacer de la producción de textos acerca de la lengua y la tradición una parte crucial del proyecto nacionalista alemán no los inhibió en la creación de una empresa cosmopolita, labrándose un mercado internacional para sus obras, y aportándoles un perfil internacional. La homogeneización estilística de los Märchen les resultó útil también aquí. Del mismo modo que los $K H M$ podían dar cuerpo a un prototipo nacional que ellos mismos habían creado en gran medida, también resultaban comparables con relatos cortados sobre el mismo molde. ¡No hay que maravillarse entonces de que el académico ruso Vladimir Propp (1968) pudiera proveer una fórmula estructural única para el cuento mágico o popular! (Bauman y Briggs 2003: 223).

La observación final sobre Propp es reveladora y puede confirmarse al revisar la literatura de la época, la del viaje científico (filológico, antropológico), que va a buscar determinados productos universalmente asequibles, y en cuya búsqueda interviene un pathos similar al de la archivación de las lenguas antes de su desaparición, y de hecho es muchas veces parte de una y la misma empresa: el cuento popular es un tesoro en bruto cuya precaria existencia en la oralidad debe ser registrada antes de que el avance de la modernidad termine de sentenciar su desaparición. El estudio de Lenz parte justamente de esta base:

Sabemos hoi que el cuento mítico, la conseja, ha existido i existe entre todas las naciones cualesquiera que sea el estado de su cultura. Pertenece por su naturaleza a la literatura anónima, esclusivamente oral, que corre en boca de todos, i se considera como mero entretenimiento en las horas de ocio. Por esta razón en la literatura oficial de las naciones de alta cultura, que enumera las obras de los grandes poetas, no encuentra lugar la conseja, i sin embargo ella junto con los demás grupos de narraciones que acabo de enumerar, i junto con la adivinanza i el canto forman casi el único alimento literario de toda la jente sencilla, que no lee diarios, porque no sabe leer (Lenz 1911: 687).

La universalidad de la forma narrativa popular tipificada en el clásico alemán (y sus antecedentes conocidos, desde ya, pero es en los Grimm que encuentra su lugar en el sistema que integra lengua, cultura y nación) es 
una forma más de superar los límites artificiales de la institución literaria, una de las expresiones fundamentales de la voluntad democratizadora del Romanticismo, en su incorporación de lo popular bajo la tutela de y procesado por el saber letrado.

"La gente sencilla", que aparece como una denominación un poco más amable que la del pueblo bajo o niedriges Volk (Lenz 1902: 5), se ve delimitada por un instrumento fundamental en la construcción moderna del estándar, el vehículo por antonomasia del print capitalism que, de acuerdo con Anderson (2006 [1983]: 43), hace posible la forma moderna de la nación y el nacionalismo: el periódico. Al igual que Lehmann-Nitsche en Buenos Aires (cfr. Prieto 1987), Lenz se había dedicado desde sus primeros años en Chile a recoger la poesía popular impresa en hojas sueltas, observando en 1919 que, si bien prosiguió en su colección "en los últimos diez años la cosecha ha sido escasa, porque ya esas publicaciones han perdido casi por completo el rumbo que tenían antes" (Lenz 1919: 513). Estas hojas, destinadas más a la lectura individual o colectiva que a la recitación, representaban de por sí una instancia más en la progresiva desaparición del género cultivado en la oralidad, ya que "la cultura creciente de las clases bajas de la población en Chile, como en todas partes del mundo, ha disminuido la afición a la antigua poesía popular" (Lenz 1919: 514). La expansión del mercado internacional de la cultura a través de una prensa masificada se traduce en la extinción no solo de un género, sino de toda una práctica cultural, de la que solo quedará el rastro que guarde el archivo $^{30}$. Finalmente, deja abierta la posibilidad de que estudios históricos y comparados de estos materiales permitan deducir cuánto de ellos pertenece en su origen a la cultura de los conquistadores españoles, cuánto a los "antepasados indios" y "cuáles rasgos se han desarrollado sólo dentro de la vida propia de la nación". Nuevamente, su posición se define entre el carácter pionero de una labor que rescata para el archivo de la ciencia y el patrimonio de la nación una forma cultural en trance de extinción y la

30 La pérdida se registra a partir de la integración en el circuito de la cultura de masas, de la reproducción técnica en serie, de la innovación técnica de la ilustración y la información, que viene a sustituir las modalidades discursivas tradicionales: "La publicación de hojas de versos ha llegado a ser cuestión mercantil de ciertas imprentas; cancioneros, llamados populares, se llenan hoi con las canciones que las zarzuelas españolas i las operetas han puesto de moda, $\mathrm{i}$ sustituyen los cuadernitos en que Guajardo, Nicasio García i otros puetas recojían sus obras. El desarrollo del periodismo llena las calles con infinitas publicaciones políticas, humorísticas i cuestiones sensacionales (crímenes i pleitos), la mayor parte con ilustraciones i mató así el interés del público de los suburbios por los toscos grabados hechos a cortaplumas" (Lenz 1919: 514). 
precariedad de la investigación sin bibliotecas especializadas (en este caso folclóricas) (ibíd.: 519).

Una exploración en profundidad de los Estudios araucanos excedería en este caso los límites del presente trabajo, aunque no quisiera dejar de poner atención sobre el lugar del relato tradicional en este tipo de estudios. En 1912, a pedido del director del Servicio Sismológico, Lenz realiza una breve investigación, publicada también en los Anales, sobre las "Tradiciones e ideas de los araucanos acerca de los terremotos". Allí da cuenta nuevamente de la autoridad obtenida en el terreno, como mediador autorizado no solo entre la tradición y la cultura letrada, entre lengua y lengua, sino también entre el pasado y el presente: es quien puede operar el deslinde entre las observaciones válidas e inválidas de los cronistas, y quien hace solo veinte años ha abierto este campo a la "investigación moderna i directa", siendo uno de los pocos "que se han dado la molestia de aprender prácticamente la lengua del indio, que es la llave de su alma” (Lenz 1912c: 754).

\section{FINAL}

Los diversos aspectos de la obra de Lenz, tal como él mismo lo formulara y algunas lecturas recientes han sabido recogerlo, integran el examen de prácticas lingüísticas y culturales diversas y hasta entonces desatendidas en un proyecto filológico que no puede reducirse sencillamente a una división en casilleros estancos (Bernaschina 2013: 131). La revisión de este proyecto filológico moderno entre el centro y la periferia (y esto no solamente en el sentido de sus desplazamientos geográficos) nos puede ofrecer hoy, es mi parecer, algo más que la ocasión de trazar genealogías prestigiosas, celebrar resistencias o condenar colonialismos lingüísticos o epistemológicos en general y de antemano. Puede contribuir a pensar los términos en los cuales la historia de la disciplina se vuelve decisiva para la historia política de la lengua misma, y cómo la presuposición de una "colonialidad" en la lengua o en la lingüística no significa solamente el traslado de moldes idénticos del centro y la periferia, sino que, en ese movimiento, puede asumir su forma más interesante al adquirir sus rasgos propios.

La idea de "economías de la lengua" quisiera aquí apuntar sobre todo al modo en el cual las múltiples y diversas labores del filólogo se organizan en torno a una tarea que, en su voluntad de autonomía, no puede más que ser profunda, decisivamente política. Lenz procura contribuir a hacer del 
español de Chile una lengua moderna, con todos sus atributos (esto es, una lengua acorde a la lógica del estándar y el patrimonio alumbrada por el capitalismo moderno) para lo cual no necesita intervenir en la discusión por lo que llama la "lengua literaria", sino trabajar en la detección, recolección, valoración y procesamiento de la materia prima de la lengua y la cultura de lo que identifica como el "bajo pueblo", señalar sus límites, su lugar en la historia y su prehistoria en el contacto, el conflicto y la mezcla que sitúa en el origen de la "diferencia chilena" que hace posible el desarrollo "sano" de una identidad nacional. Sin dejar nunca el lugar lúcido y extrañado del extranjero, Lenz brega por un espacio relativamente autónomo para su práctica, el de una gramática descriptiva, científica y no prescriptiva y punitoria, procurando, a partir de su gestión (acopio, ordenamiento, valoración, interpretación) del archivo de la lengua nacional, convertirse no ya en vocero del Estado, sino en un interlocutor válido para intervenir, ahora sí, sobre las políticas de la lengua legítima en el espacio de su producción, la escuela. Esto puede observarse en la puesta en escena de sus conferencias acerca de la necesidad de la gramática en la escuela $(1912 b, 1920)$, pero esa ya es materia de otro estudio.

\section{REFERENCIAS BIBLIOGRÁFICAS}

Agamben, Giongio. 2008. El reino y la Gloria. Una genealogía teológica de la economía y el gobierno. Homo Sacer II, 2, trad. de E. Castro, F. Costa y M. Ruvituso. Buenos Aires: Adriana Hidalgo.

Alonso, Amado. 1938. "Rodolfo Lenz y la fonética del castellano". Homenaje a la memoria del Dr. Rodolfo Lenz: Anales de la Facultad de Filosofía y Educación de la Universidad de Chile, 2, 1: 11-17.

Altschul, Nadia R. 2012. Geographies of Philological Knowledge: Postcoloniality and the Transatlantic National Epic. The University of Chicago Press.

Anderson, Benedict (2006 [1983]). Imagined Communities. Reflections on the Origins and Spread of Nationalism. Londres y Nueva York: Verso.

Barros Arana, Diego y Rodolfo Lenz. 1893. "La lingüística americana. Su historia y su estado actual", Anales de la Universidad de Chile, 84. Separata.

Bauman, Richard y Charles L. Briggs. 2003. Voices of Modernity. Language Ideologies and the Politics of Inequality. Cambridge, CUP.

Benfey, Theodor. 1869. Geschichte der Sprachwissenschaft und orientalischen Philologie in Deutschland seit dem Anfange des 19. Jahrhunderts mit einem Rückblick auf die früheren Zeiten. Múnich: Cotta.

Bergounioux, Gabriel. 2002. La séléction des langues: darwinisme et linguistique. Langages 36(146): 7-18. 
Bernaschina, Vicente. 2013. "Rodolfo Lenz, 150 años en disputa con el imperio de la lengua", Universum, 28, 2: 117-138.

Blommaert, Jan. 2005. Discourse. A Critical Introduction. Cambridge: CUP.

Blommaert, Jan y Jef Verschueren. 1998. "The Role of Language in European Nationalist Ideologies"; en Schieffelin, Bambi B., Kathryn Woolard y Paul V. Kroskrity (eds.). Language Ideologies. Practice and Theory. Nueva York y Oxford: Oxford University Press, pp. 189-210.

Bourdieu, Pierre. 1982. Ce que parler veut dire. L'économie des échanges linguistiques. París: Fayard.

Calvet, Louis-Jean. 1974. Linguistique et colonialisme. Petit traité de glossophagie. París: Payot.

Chávez Fajardo, Soledad. 2011. "Ideas lingüísticas de Lenz en los paratextos de su Diccionario etimológico de las voces chilenas derivadas de lenguas indígenas americanas: vigencia y urgencia en el español de Chile", Lenguas Modernas 38: 83-106.

Concha Ferreccio, Pablo. (2015). La genealogía filológica: regionalismo literario y comunidades imaginadas en Brasil y Chile. Tesis de maestría, Universidad de Chile, Facultad de Filosofía y Humanidades.

Del Valle, José. 2000. "Monoglossic policies for a heteroglossic culture: misinterpreted multilingualism in modern Galicia", Language and Communication 20: 105-32.

Del Valle, José y Luis Gabriel-Stheeman (eds.). 2002. The battle over Spanish between 1800 and 2000. Language ideologies and Hispanic intellectuals. London \& New York: Routledge.

DeRriDA, JACQUES. 1996. Le monolinguisme de l'autre ou la prothèse d'origine. París: Galilée [trad. cast. de Horacio Pons, Buenos Aires: Manantial, 1997].

EnNis, JuAn Antonio. 2012. "Rudolf Lenz en la encrucijada criolla", Signo \& Seña 22: 181-214. 2014a. "August Schleicher: los dos cuerpos de la lengua", Revista argentina de historiografia lingüistica, 6, 2: 107-121.

2014b. "El uso, la propiedad y el valor en el debate de la lengua americana", Anclajes XVIII, 2: 32-47.

2015. "El origen de la lengua y los comienzos de la lingüística: una pregunta del siglo", introducción a Jacob Grimm. Sobre el origen de la lengua, Buenos Aires: UNTREF, pp. 9-71.

Errington, Joseph. 2008. Linguistics in a Colonial World, London y New York, Blackwell.

Escudero, Alfonso M. 1963. "Rodolfo Lenz”, Thesaurus. Boletín del Instituto Caro y Cuervo. Tomo XVIII, $\mathrm{n}^{\circ}$ 2: 445-484.

Foucault, Michel. 2005 [1966]. Las palabras y las cosas. Una arqueología de las ciencias humanas, trad. de E. C. Frost. Buenos Aires: Siglo XXI.

Haugen, Einar. 2001 [1972]. "The ecology of language", en Fill, Alwin y Peter Mühlhäusler (eds.). The Ecolinguistics Reader. Language, Ecology and Environment. Londres y Nuva York: Continuum, pp. 57-66.

KoERner, E. F. K. 1989. "August Schleicher and linguistic science in the second half of 19th century". Practicing Linguistic Historiography. Amsterdam y Filadelfia: John Benjamins, pp. 325-375.

Lefmann, Salomon. 1870. August Schleicher. Skizze. Leipzig: Teubner.

Lenz, Rodolfo. 1892. "La fonética". Anales de la Universidad de Chile 81: 901-924.

Lenz, Rudolf. 1893a. "Beiträge zur Kenntnis des Amerikanospanischen", Zeitschrift für romanische Philologie XVII: 188-214.

Lenz, Rodolfo. 1893b. "Enseñanza de idiomas estranjeros (frances, ingles i aleman)", Anales de la Universidad de Chile 84: 245-256.

1893c. "Nacionalidad y lenguaje", Revista Nacional, Segunda serie, XVII: 35-47. 
1894. "Ensayos filolójicos americanos I. Introducción al estudio del lenguaje vulgar de Chile en Anales de la Universidad de Chile", Anales de la Universidad de Chile 87: 113-132.

1898a. "Crítica de la Lengua Auca, del señor Raoul de la Grasserie", Anales de la Universidad de Chile 101: 157-175.

Lenz, Rudolf. 1898b. "Kritik der Langue Auca des Herrn Dr. Jur. Raoul de la Grasserie. Eine Warnung für Amerikanisten", Verhandlungen des Deutschen Wissenschaftlichen Verein, tomo IV. Separata. Valparaíso: Imprenta del Universo de Guillermo Helfmann.

1902. Die indianischen Elemente im chilenischen Spanisch inhaltlich geordnet. Halle: Niemeyer.

Lenz, Rodolfo. 1910. Los elementos indios del castellano de Chile. Estudio lingüístico $i$ etnolójico. Primera parte. Diccionario etimolójico de las voces derivadas de lenguas indijenas americanas. Santiago: Imprenta Cervantes.

1911. "Un grupo de consejas chilenas. Estudio de novelística comparada precedido de una introducción referente al oríjen i la propagación de los cuentos populares", Anales de la Universidad de Chile, 129: 685-764.

1912a. "Los elementos indios del castellano de Chile", extracto de las Actas del $X V I I^{\circ}$ Congreso Internacional de Americanistas. Buenos Aires: Coni.

1912b. ¿Para qué estudiamos gramática? Conferencia dada en la Universidad de Chile. Santiago: Imprenta Cervantes.

1912c. "Tradiciones e ideas de los araucanos acerca de los terremotos". Anales de la Universidad de Chile 130: 753-771.

1919. "Sobre la poesía popular impresa de Santiago de Chile. Contribución al folklore chileno". Anales de la Universidad de Chile 143: 511-622.

1920. La enseñanza del castellano i la reforma de la gramática. Memoria presentada al honorable Consejo de Instrucción Pública. Santiago. Soc. Imprenta i litografía Universo.

1924. Estudio sobre los indios de Chile. Extracto de Publicaciones del Museo de Etnología y Antropología de Chile, tomo IV, $\mathrm{n}^{\circ} 1$ y 2, pp. 147-160.

1928. El papiamento. La lengua criolla de Curazao. La gramática mas sencilla. Santiago: Anales de la Universidad de Chile.

1935 [1920]. La oración y sus partes. Estudios de gramática general y castellana. Madrid: Centro de Estudios Históricos.

1940. "Dialectología hispanoamericana”, en Lenz, Rodolfo, Andrés Bello y Rodolfo Oroz. El español en Chile, traducción, notas y apéndices de Amado Alonso y Raimundo Lida. Buenos Aires: Instituto de Filología.

Ludwig, Ralph, Peter Mühlhäusler y Steve Pagel (eds.). 2016. Linguistic Ecology and Language Contact. Cambridge: CUP.

Malkiel, Yakov. 1968. "Hispanic Philology", en Sebeok, Thomas (ed.). Current Trends in Linguistics IV: Ibero-American and Caribbean Linguistics. París y La Haya: Mouton.

Meyer-LüBke, Wilhelm. 1920. Einführung in das Studium der romanischen Sprachen. Heidelberg: Winter, $3^{\text {a }}$ edición.

Mufwene, Salikoko. 2004. The Ecology of Language Evolution. Cambridge: CUP.

MüHLHäUSLER, Peter. 1996. Linguistic Ecology. Language Change and Linguistic Imperialism in the Pacific Region. Londres y Nueva York: Routledge.Petursson, Magnus. 1989. "Rodolfo Lenz y la Fonética" en Actas del Octavo Seminario de la Investigación y Enseñanza de la Lingüística. Universidad de Santiago de Chile y Sociedad Chilena de Lingüística, pp. 3-11. 
Petursson, Magnus. 1989. Rodolfo Lenz y la fonética. En Actas del Octavo Seminario de la Investigación y Enseñanza de la Lingüistica, pp. 3-11. Santiago: Universidad de Santiago de Chile y Sociedad Chilena de Lingüística.

Philipson, Robert. 1992. Linguistic Imperialism. Oxford: OUP.

Pratt, Mary-Louise. 1995. Ojos imperiales. Literatura de viajes y transculturación. Bernal: Universidad de Quilmes.

Prieto, Adolfo. 1987. El discurso criollista en la formación de la Argentina moderna. Buenos Aires: Sudamericana.

Rabanales, Ambrosio. 2002. "Rodolfo Lenz", Onomazein, no 7: 161-181.

RoJas, Darío. 2011. "Voces usadas en Chile (1900): las cartas de Aníbal Echeverría y Reyes a Rodolfo Lenz”, Onomazein 24 (2011/2): 349-361.

SCHLEICHER, AUGUST. 1862. Briefe über die Erfolge einer wissenschaftlichen Reise nach Litauen. Separata de los cuadernos de octubre de 1852 de los Sitzungsberichte der philosophischhistorischen Classe der kaiserlichen Akademie der Wissenschaften, vol. IX.

1860. Die deutsche Sprache. Stuttgart: Cotta.

Schuchardt, Hugo. 1885. Über die Lautgesetze. Gegen die Junggrammatiker. Berlín: Oppenheim.

Sousa, Silvio Moreira de y JohanNes MücKe. 2016. “Addendum to Networking and obstacles to the development of the language sciences as reflected in the correspondence of Rodolfo Lenz and Hugo Schuchardt", History and Philosophy of the Language Sciences. https:// hiphilangsci.net/2016/02/17/networking-and-the-obstacles-to-the-development-of-thelanguage-sciences/\#comment-9881

Valencia, Alba. 1993. "El legado de tres maestros: Lenz, Oroz y Rosales". Revista de Lingüistica Teórica y Aplicada (Concepción) 31: 137-162.

VELLEMAN, BARRY. 2008. "La imagen y los ecos del lingüista profesional: la correspondencia de Rodolfo Lenz”, RLA. Revista de Lingüística Teórica y Aplicada, vol. 46, nº 1: 11-28.

Vilches, Roberto. 1938. "Bibliografía de las publicaciones científicas y pedagógicas der Dr. Rodolfo Lenz" (Tomada de la Revista de Bibliografía Chilena y Extranjera, Santiago 1914, y completada por Roberto Vilches). Homenaje a la memoria del Dr. Rodolfo Lenz, Anales de la Facultad de Filosofia y Educación de la Universidad de Chile, II, 1: 160-169.

Voegelin, C. F., F. M. Voegelin y Noel W. Schutz. 1967. "The language situation in Arizona as part of the Southwest culture área". En Hymes, Dell y William E. Bittle (eds.). Studies in Southwestern Ethnolinguistics: Meaning and history in the languages of the American Southwest. The Hague: Mouton. 
